\title{
Central ethical considerations for masters and doctoral research in business and management studies
}

\author{
Dan Remenyi \\ Chalmers University of Technology. Gothenburg, Sweden \\ Remenyi@COMPUSERVE.COM
}

Received June 1998

\begin{abstract}
The subject of ethics is important in university research for a number of reasons. All masters or doctorate candidates need to be familiar with the issues involved in order to avoid any problems or criticisms of their work. This article addresses a wide range of issues including what should be researched. how the research should be conducted. how evidence should be collected and processed and how the finding should be treated. Issues related to plagiarism. thief of ideas, measuring instruments and choice of samples are also discussed. Finally the question of how much work may actually be done by others is also addressed.
\end{abstract}

Key words: ethics, university research, $\mathrm{PhD}$ research, masters degrees, collecting evidence. processing evidence. plagiarism, thief of ideas, measuring instruments, choice of sample.

\section{Introduction}

The objective of this article is to stimulate a debate among academics, especially business and management scholars. It is also hoped that it will offer first time research candidates some ideas, or even a framework, to help consider the complex issues relating to ethics in respect of masters and doctoral research in business and management studies. As ethics involves consideration of right and wrong (Singer. 1994; Miesing \& Preble, 1985; Taylor, 1975), it is difficult to write this article without sounding prescriptive. However, it is specifically not the intention of the article to attempt to offer a definitive set of guidelines for the masters or doctoral researcher to apply. Rather it raises a number of issues which should be considered if a major research project for a masters or doctorate degree is not to be queried on the grounds of questionable ethical practices.

By its very nature this article can only express the personal views, values and attitudes of the author, as well as relate and comment on his personal experiences.

\section{Background}

The subject of ethics' is important in university and business school research for a number of reasons. All masters or doctorate candidates need to be familiar with the issues involved to avoid any problems or criticisms of their work. This is especially true of business and management scholars who often find themselves researching in sophisticated corporate settings, sometimes with only occasional supervision and thus they need to have a firm understanding of what is considered the rights and wrongs of the practice of research.

To appreciate the extent of the concern about ethical issues in this area it is important to focus on the objectives of university and business school research at this level. The objective of both masters and doctoral research. but especially doctoral research, is to establish the candidate as a scholar by demonstrating that he or she is, at least to some extent, an authority? in the chosen field of study to the ex- tent of having added something new and valuable to the body of knowledge.' In so doing it is also necessary to show a clear and thorough understanding of research methodology. The researcher should achieve this in such a way that no one individual or institution has been taken advantage of, and that no one individual or institution has been harmed directly or indirectly by the research process or by the subsequent dissemination of the research findings. The findings should be presented as objectively as possible with care being taken not to suggest. overtly or implicitly. that more has been accomplished by the researcher than may actually be the case. In addition there is an ethical issue which some researchers have to face when they discover business practices which are either illegal or are questionably unethical or embarrassing.

\section{Research and trust}

University and husiness school researchers, especially those working towards a masters or doctorate are in a privileged position. In the case of doctorate candidates. such researchers are working towards the highest degree which a university offers by examination and this degree will not only give them a qualification. but will actually change their status in society by giving them a distinctive title. Further, universities and business schools place a high level of trust in the candidates for these degrees. Universities generally assume that master and doctorate candidates will perform their work to the highest ethical standards and thus except for the advice offered hy their supervisors or promoters." these researchers in the business and management field, are generally left alone to work independently." In the field of business and management studies. except for a certificate stating that the research is the own personal work of the degree candidate. universities usually require no other verification of the ethical standards used during the research work. despite the fact that it is relatively easy to cheat with the results of business and management research.' 
Hand in hand with this trust placed in the candidates by the university. members of the public, including business people. will generally be prepared to discuss their affairs with university degree candidates much more frankly and openly than they would with other people including nonacademic researchers. Information about business is usually sensitive and it is therefore important that the researcher understand the ethical issues involved in being taken into the confidence of the informants.

\section{Implications of a breach of trust}

When a trust is breached by some sort of unacceptable behavior on the part of the researcher, universities normally take the matter seriously. It is worth pointing out that in the few cases where a university or a business school withdraws a degree from a graduate it is inclined to be because some major ethical irregularity has occurred during the candidate's pursuit of the degree. This of course is a most unusual occurrence.

\section{Some central issues}

The first part of this article will address ethical issues which can create problems, even when the researcher is trying hard to ensure the integrity of the research. Later other issues will be raised concerning how research can be tainted and thus made questionable by poor thinking and practices.

There are a number of key issues which need to be carefully addressed and carefully thought through by the masters and doctorate researcher if the integrity of the research is to be ensured. These include, but are not limited to, what should be researched, how the research should be conducted, who is paying for the research and what should happen to the results of the research. Of course what is considered ethical will vary enormously from individual to individual and from institution to institution and thus this article can only suggest some tentative thoughts on important issues. In addition many of the ethical matters concerned do not have clear houndaries and thus there are many grey areas about which the researcher should be aware.

\section{What should be researched?}

From a broad societal or macro point of view there are a number of research subjects which may cause ethical concern among certain groups of people. These include genetic engineering, total or whole body transplants, the use of animal organs in human transplant surgery, germline gene therapy (Equinox. 1996), strategic defense techniques such as those which have been labeled as Star Wars. nuclear power and artificial intelligence (Remenyi \& Williams, 1996). However from a business and management perspective the areas of concern would be related to less lofty issues such as concerns surrounding marketing practices which might infringe on privacy, or which might exert excessive influence or coercion on prospective buyers. Research into ways of controlling and manipulating the work force could be considered questionable. Information systems which had a built-in bias in favor of financial institutions. such as banks or insurance companies, at the expense of their clients would also be questionable, and research in this field might be considered not quite ethical.

In general there are a large number of business and management research issues which could not be questioned on the grounds of any ethical considerations and it is probably sensible for research candidates to stay within these parameters, or if not, then be aware of the objections which could be raised by those who would query their conduct on ethical grounds.

\section{How the research should be conducted?}

In the business and management environment how the research should be conducted is perhaps of greater concern in an ethical sense to the typical masters and doctorate candidate than the question of what is being researched.

There are three major aspects of this how question. In the first place there is the issue of the collection of evidence," and in the second there are the problems associated with processing the evidence and finally there is the use of the findings.

\section{Evidence collection}

Clearly there has been in the past a dark side to research, especially with regards the collection of evidence. Atrocities were perpetrated by $\mathrm{Nazi}$ and Japanese scientists before and during the 1939 to 1945 war in the name of research, and these acts of cruelty and murder have been totally condemned by all civilized nations and peoples.".111 In a much less grotesque way scientific experiments have been conducted in the post-war period on volunteer individuals causing them physical and sometimes mental pain and suffering." This type of work is now considered unacceptable, despite the willingness of the participants.

Similarly, in some societies experiments on animals, ${ }^{12}$ especially those which result in the taking of their lives are now considered to be only justifiable in special cases where there is no other alternative, and the knowledge so acquired is of particular importance to medical science (Haldane, 1930; Medawar, 1986; Singer, 1995)

In fact Medawar (1986) takes a strong position on this issue stating that 'experimental animals are a moral disfigurement of medical science'.

In a university context, experiments with people and animals usually, if not always, require approval from the University's ethics committee and this is not always easy to obtain. It is essential to explain to those persons involved in experiments exactly what is being proposed and to council them about all the possible outcomes of the experiment well in advance of the experiment actually taking place.

When researching in the business and management field at doctoral level, experiments are unusual, especially in South Africa and the United Kingdom. ${ }^{12}$ Rather, research is performed by collecting evidence from informants either through the use of questionnaires or through interviews using an interview schedule, or perhaps through participant observation or through action research approaches or methodologies. 


\section{Openness with the informants}

In business and maragement studies the informants or participants in the study need to know a number of things and to be given a series of assurances (Sekaran, 1992). The main issues are as follows:

1. It is imperative that the researcher does not have any hidden agendas ${ }^{14}$ such as those of Stanley Milgram in the experiment described above.

2. It is essential that the researcher be fully open and honest with the informants and participants. This means that the informants and participants should be made aware of exactly why the evidence is required and exactly what will be done with it once the research has heen completed.

3. It is necessary for the researcher to declare if he or she has any connections or relationships with organizations or individuals which could in any way be construed to be competitive to the informant or his or her organization. Thus anything which could remotely relate to a conflict of interest needs to he specifically dealt with in advance of any evidence being revealed.

4. Where an informant does not wish to have his or her name associated with the evidence. this request should be meticulously respected.

5. The researcher should not obtain evidence from informants under duress. Thus it would not be acceptable if a researcher was to have the managing director of an organization insist that the staff complete a questionnaire if the individuals involved did not wish to do so. The informant should be told that he or she may withdraw from the interview at any time without there being any recriminations.

It is usual for the informants or participants to be aware of the final use of the evidence. and if at any stage the researcher wants to change how the evidence will be used. or to use it for additional purposes. it is important that he or she seeks the permission of the informants to so do. This is an especially important issue in business and management studies because the evidence being collected might be commercially sensitive and it would he regarded as unethical if the researcher was to use the evidence to profit or to have others profit at the expense of the organization being researched.

Appendix 1 shows a code of ethics for research students when collecting evidence and dealing with informants which is used at a univesity in South Africa and a business school in the United Kingdom. This is supplied to show a relatively comprehensive list of issues rather than to suggest any particular set of guidelines.

\section{Integrity of the evidence}

The verification of evidence is important. The researcher may feel that the evidence has not been honestly presented by the informant and in such cases an attempt should he made to verify it." "To present evidence in an unquestioned way. which the researcher feels is suspicious would not be ethically acceptable. Thus the researcher needs to be actively honest rather than passively honest in the presentation of his or her evidence and research findings.
It is also sometimes possible that the researcher misunderstood the evidence and this needs to be checked. For example, when using the case study method of evidence collection the researcher may offer the transcript of the case to one or more of the informants to establish that the situation was correctly understood and properly recounted in the written version.

It is sometimes believed that the original source of the evidence, for example a transcript of an interview. or copies of the original questionnaire. should be kept for a period of time. say somewhere between two and five years. to allow other researchers access to the data. ${ }^{\text {th }} \mathrm{A}$ good example of the need to retain data is the controversy surrounding the research conducted by Sir Cyril Burt (Medawar. 1986) and which lead to profound changes in the education system in the United Kingdom. Wadeley (1991) suggests that if Sir Cyril Burt had retained his data and made it publicly available then the issue of whether or not he falsified the data used would have heen easily resolved. ."

\section{Processing of the evidence}

The researcher needs to give considerable attention to the ethical issues related to the processing of the evidence. If the evidence is quantitative then the concerns are to do with numerical and mathematical accuracy which is relatively easy. Any attempt to window dress or manipulate and thus distort the evidence is of course unethical. as is any attempt to omit inconvenient evidence. In statistical terms this does not mean that outliers have to always be included in the numbers. but it does mean that the occurrence of such outliers should be reported as part of the findings and a reason supplied for not including them in the statistics."

In the case of qualitative evidence. the issues are more complex and sometimes more difficult as the researcher has more subjective evidence to work with. Here the question of giving appropriate importance and thus weight to statements and opinions becomes a central issue and the researcher needs to take great care to halance his or her approach. This is a difficult line to tread as it is important that the research should not he overwhelmed with personal biases. ${ }^{14}$ It is not a useful or rational strategy to tabricate evidence or to deliberately misinterpret it. as a masters or doctoral degree does not rely on the candidace tinding or proving a particular result. Even when hypotheses or theoretical conjectures are rejected. the research is perfectly valid and there is no reason why such findings should not lead to the awarding of the degree. even a first class or cum laude degree.

Sub-conscious bias on the part of the researcher is a problem. Of course triangulation may be used to help in this respect, but in the final analysis an argument based on a judgment is always required (Collins. 1994). This may not he easy to make with personal prejudices playing an overtly influential and important role. The hias problem has teen well described by Hubbard (1979) when she said:

The mythology of science asserts that with many different scientists all asking their own questions and evaluating the answers independently. whatever personal bias creeps into their individual answers is cancelled out when the large picture is put together. 
This might conceivably be so if scientists were women and men from all sorts of different cultural and social backgrounds who came to science with very different ideologies and interests. But since, in fact, they have been predominantly universitytrained white males from privileged social backgrounds. the bias has been narrow and the product often reveals more about the investigator than about the subject being researched.'

With regards research findings, it is important that these are honestly presented and not produced in such a way as to simply support the opinions or prejudices of the researcher. This is indeed hard to accomplish. Ideally the researcher is trying to apply disinterested intellectual curiosity (Trevelyan. 1942). but this is almost impossible as was pointed out by Gould (1980) when he said:

'Science is not an objective, truth-directed machine, but a quintessentially human activity, affected by passion. hopes, and cultural biases. Cultural traditions of thought strongly influence scientific theories.'

Sometimes, if not frequently, personal bias is so subtle that the researcher is not even aware of it. In fact many would argue that a researcher should not attempt to compensate for this bias, but should simply state clearly the possible biases involved and allow the readers to compensate for these themselves.

\section{Using of the findings}

Although the researcher will ultimately have little control over this issue, it is important that the intention of the research is that the findings will be used for ethical purposes. Thus research which is conducted for the purposes of perpetrating, for example, a fraud or dishonest practice has no place in a university or business school. However the definition of fraud or dishonest practice is indeed diflicult to both define and discern as has been pointed out in a recent article in The Times of London (May 14, 1998: 1) which revealed that

'Covert supporters of the tobacco company Philip

Morris made contributions to the Lancet and advised

a Commons select committee as part of a concerted

effort to blunt concerns about passive smoking ...'

Furthermore the findings of research conducted by masters and doctoral students need to be placed in the public domain. This is in keeping with the general spirit of a university, as well as being in recognition of the fact that most universities and businesses are funded to a large, or at least substantial extent, from public money. Sometimes an informant will give a researcher access to evidence on the grounds that it should not be immediately released in to the public domain. This practice is not really in the spirit of academic research. Some universities, although they allow restrictions to be placed on the publishing of evidence of this type, will not allow the degree to be finally awarded, and thus the candidate will not graduate, until the research evidence and findings are released into the public domain. Other universities simply inpose a time limit, such as one year, after which the finding are placed in the library.
Of course it is expected that research conducted for a higher degree will only be presented to a single university towards the award of a single degree. It would not be considered acceptable for the findings to be used for a number of different degrees at different institutions.

\section{Funding the research}

Doctoral research is often funded by the individual candidates themselves with, in many, if not most instances, subsidies from the state in one form or another. Only a limited amount of doctoral research is sponsored by private interests such as commercial organisations. In the case of privately funded academic research it is important that the interests of the funder do not influence the research approach or the findings of the work in any way. Thus the central issue here is the possibility of there being a conflict of interest. If doctoral research has been funded then it is essential for the candidate to explicitly declare this to the university and to the supervisor at the outset of the work. All informants who supply evidence for the research should also be aware of this. Of course the external examiner or examiners should also be informed of such arrangements.

\section{Some rules relating to the performance of the work itself}

There are a number of ethical issues relating to the more routine aspects of research work than those mentioned above and these include plagiarism, fudging references, measuring instrument construction, choosing a sample, assistance from others, misrepresentations of work done, to mention only a few points.

\section{Plagiarism}

Occasionally plagiarism is a problem as sometimes business and management researchers may rely too heavily on the work of others to the extent of copying large tracts of work without given acknowledgment to the source. This is obviously considered unethical and can lead, in extreme cases, to candidates being excluded from the university. As a general rule, although research candidates are required to rely heavily on the ideas of others at the outset of the research, these ideas need to be appropriately referenced. In addition, a dissertation, although it should include some quotations from other works, should not be too reliant on this type of printed evidence. It is sometimes said that a quotation from another piece of work should not be more than 100 words in length. Of course these are not hard and fast rules, but rather rough guidelines which if approximately followed will help avoid arguments. ${ }^{21}$

Sometimes it is argued that there is an element of plagiarism present when a candidate attempts to replicate an experiment conducted in another country or conducted in another set of circumstances. This view is somewhat controversial and provided there is no outright copying of a previous dissertation the author would not accept that replicating an experiment is essentially an act of plagiarism, especially if the original work is correctly referenced. 


\section{Theft of ideas}

Ideas can be stolen. A researcher may overhear others talking about possible areas of research or preliminary findings and pursue these research ideas without reference to their origin. When this happens very unpleasant circumstances arise especially if ideas are stolen from research students or junior members of staff by senior members of staff. This is a particularly difficult area as it is not possible to have much control over ideas and thinking. According to the Guardian Weekly - Le Monde section (1988)

'Now in the past two decades. the ethics of the scientific profession (at least among mathematicians) have become so degraded that wholesale plundering of ideas (and particularly at the expense of those in no position to defend themselves) has become almost the general rule among scientists. It is at any rate tolerated by all, including in the most glaring and ubiquitous of cases.

Ideas have also been stolen by referees who see the ideas in academic papers which they have been asked to review. It is also possible to had an idea stolen by members of funding boards who are also given early access to new ideas which require money to proceed.

The only safe position to take to prevent any such possible accusation of stealing ideas is for a researcher to acknowledge any and all sources of ideas, be they in writing from journals or books. or verbally from presentations. conversations or discussions. From the perspective of preventing ideas from being stolen, the best course of action is not to discuss interesting thoughts within the ear shot of colleagues until the ideas are reasonably well developed. This will help reduce such incidents although clearly it will not eliminate them. It is very difficult to protect ideas from unscrupulous referees.

\section{Fudging references}

In a way related to plagiarism. but not quite of the same severity, is the issue of quoting an authority without having actually read the original reference, but rather having seen it published in someone else's work. It is considered unacceptable to do this. Any reference made in a dissertation to the work of another should only be made if the research candidate has read the original themselves. However it is acceptable to use the 'cited by' approach. Thus if in reading a book by Joe Bloggs, the eminent scientist Altert Einstein is quoted. then the candidate may use Einstein's words provided he or she states that the quotation was cited by Joe Bloggs in this book and a full reference is given to this work.

\section{Measuring instrument construction}

Constructing a measuring instrument can be a critical part of research in the business and management field and there are many ethical issues around how this is handled and how the evidence which is collected with the measuring instrument is treated.
Increasingly. personal questions are becoming unacieptable. Issues of age. race. sex. educational standard achieved et cerera are no longer regarded as issues atout which researchers can expect to ohtain iniormation. In fact some would argue that this has become an ethical issue.

Researchers are sometimes templed to state that the questionnaire is anonymous. while at the same time placing some sort of indicator on the paper 10 allow its origin to the determined. The justification which may be given for this is to put the researcher in a position to be able to chase up those who have not completed the questionnaire. Such practice is generally considered to be unacceptable

Using leading questions which have a high probability of being answered in the manner desired by the researcher is also ethically questionable.

\section{Choosing a sample}

The choice of the sample used can dramatically affect the results of the research and thus this is an important issue. However it hecomes an ethical issue if the sample is manipulated to show a desired result

This may come about in two ways.

1. The researcher may choose only informants whom he or she knows will have the opinions which the researcher espouses.

2. The researcher may discard evidence from informants who do nol comply with his or her views.

Samples need to be estahlished honestly which means they can produce results which will not necessarily support the views and/or prejudices of the researcher. Inconvenient or conflicting evidence should be directly addressed and not hidden or ignored.

\section{Assistance from others}

The amount of assistance which a masters or doctoral candidate may obtain from others is a delicate issue. There have been cases where even minor help has resulted in questions being asked by examiners and this has produced problems which have delayed the auarding of the degree. An example which comes to mind is where a candidate has a science student write a computer program for him to help with the analysis of some evidence. This caused an examiner's inquiry. However this particular incident occurred a few years ago and would probably not be treated in the same way today.

A potentially more serious incident took place recently where a masters student approached a member of staff with the request for help in writing his dissertation. The candidate said that due to pressure of work in his salary earning job he was unable to complete the dissertation on time and he would pay a large sum of money for help. The implication was that the member of staff would actually write the dissertation for him. Clearly this was totally unacceptable and the offer was declined.

There is much anecdotal evidence of considerable assistance being given to degree candidates. Of course supervisors may extensively assist candidates in a number of ways. but care needs to be taken so that the dissertation does not hecome predominately the work of the supervisor rather than that of the student. Research degree candidates and 
their supervisors sometimes publish joint papers and this is a perfectly acceptable way in which they may work together and the supervisor may give considerable help to the student."

If help is sought by the candidate from professionals such as statisticians then the question of whether a payment is made may become an issue. Many universities would regard paying for help of this kind as being ethically questionable."

\section{Misrepresentations of work done}

Because of the high degree of trust placed in researchers it is not difficult to exaggerate the amount of work actually performed. Candidates can purport to have conducted 30 interviews when they have actually only had 20 . Interviews and questionnaires can be fabricated.

The amount of work undertaken for the literature review may also be exaggerated. They can say that they consulted texts when they did not. This can lead to misunderstanding of quotations especially with regards to their context.

Any such misrepresentation is clearly unacceptable and furthermore is highly dangerous. Candidates can be found out and this type of misrepresentation would probably lead to the termination of their registration at the university.

\section{Responsibility to the greater community}

So far this article has only addressed the researcher's ethical responsibility to the integrity of the research itself and to the university at which the researcher is registered. There is however another important dimension to the ethical issue and that is the researcher's responsibility to the greater community or the society of which he or she is part.

\section{Discovery of unlawful or unethical practices}

A major ethical issue which a business and management researcher may face relates to the discovery or uncovering of some misconduct within the organization being researched. This of course is not likely to be revealed through survey research, but rather through case study research. There are three levels at which this may occur and these relate to

- unlawful or illegal conduct

- unsatisfactory practices which endanger staff

- embarrassing revelations.

\section{Unlawful or illegal conduct}

It is possible for a research degree candidate, when conducting an in-depth case study to discover unlawful or even illegal practices. An example of this would be the discovery that some sort of criminal act was being perpetrated on the firm by the employees, or perhaps by the employees on the firm's customers. Such a circumstance presents a difficult situation for the researcher. The law may require that the presence of criminal acts or serious fraudulent practices should be reported to the authorities and it is essential that the researcher comply with the law. This of course may well mean the end of the research exercise for the degree candidate with the organisation and people involved in this unfortunate situation. If this happens during an important case study then the researcher's work may be set back by a considerable amount of time. However, this inconvenience, no matter how great, should not lead to the researcher refusing to comply with the law.

\section{Unsatisfactory practices which endanger staff}

In some respects an even more difficult circumstance may arise where the business and management researcher discovers that some important business practice which for example, is essential to worker safety, or to customer safety, is not being complied with. What is happening or not happening may not be a criminal act in terms of any legislation, but nonetheless the organisation may be behaving totally unacceptably. The difficulty here is that although nothing actually illegal is taking place, the situation as discovered by the researcher is highly unsatisfactory.

There are many gray areas in these circumstances and thus it is very hard to give any generic advice. All that may really be said is that the researcher needs to carefully discuss these situations with his or her supervisor and that an appropriate course of action should be taken. This will usually mean taking the discovery of the questionable situation up with senior officials of the organisation concerned. As already stated, this course of action may well mean the end of this part of the research exercise for the degree candidate with the organisation and people involved.

\section{Embarrassing revelations}

Situations falling under the category of embarrassing revelations include issues such as special relationships between individuals within the firm and special arrangements between members of the firm and other outside organisations. An example would be where the sales director has been using his family connection to obtain favored supplier status with an important client. This might or might not include the use of excessive business gifts to the family member concerned. Another example might be the discovery of an alcoholic drinking problem. Such situations are probably best left alone as they will no doubt come to light sooner or later and the researcher is probably better off ignoring them.

Fortunately these type of situation do not arise often and thus the business and management researcher is not frequently plunged into the type of crisis described here. However when they do occur they are usually distinctly harmful to the research.

\section{Summary and conclusion}

Academic research in the business and management field is a challenging, but also a very rewarding activity. Ensuring that research is performed correctly in the sense of heing conducted in an acceptable way and that its findings add something of value to the body of knowledge, is extremely demanding. It is not surprising therefore that few people succeed as competent academic researchers, especially at the doctorate level. The difficulty of performing quality research may have been in the mind of H.G. Wells (1925) when he said 'Fools make researchers and wise men exploit them'. 
Of course those who succeed at research do sometimes achieve fame and fortune, win Nobel prizes, register new inventions, become international management gurus or start up computer corporations or biotech companies and make millions of dollars, although it must be admitted that this is a relatively rare occurrence experienced by only the very best in the field. The subject of ethics is in its own right one of considerable controversy and sometimes different individuals take strongly opposing positions. According to Ewing (1965)

'Ethics, like other branches of Philosophy, is a subject where very wide differences of opinion exist between competent authorities. ${ }^{2 ?}$

In a general sense what is right and wrong is a question which has puzzled humankind and many of our greatest philosophers for millennia (Aristotle, 1976; Kant, 1784; Mills, 1863; Russell, 1946). And there are no clear universal answers to the question of ethics or morals, even within a relatively homogeneous cultural group such as Western society (Lacey, 1982). As Wittgenstein (1990) pointed out 'We feel that even if all possible scientific questions can be answered, the problems of life have still not been touched at all.'

And morality and ethics is one of the central problems of life.

Even within a single institution such as a university or a business school there may be substantially conflicting views about what is right and wrong with regards as to how research should be conducted. The problem is that although everyone will immediately agree that it is unethical to cheat, there will inevitably be disagreements as to what actually constitutes cheating. Even when it is agreed that cheating has taken place there is the difficult question of how material the cheating was and what may reasonably be done about it. However increasingly ethics is a subject which is attracting the attention of managers, consultants and academics (Wheatley, 1992) and London Business School has established a chair of Business Ethics, and thus it is likely that this will produce a better and wider understanding of the issues involved.

It is however interesting to note that Bertrand Russell (1976), perhaps in one of his more playful moods, pointed out the highly subjective nature of ethics by saying that: 'Ethics is in origin the art of recommending to others the sacrifices required for co-operation with oneself.

It is perhaps unfortunate, although in fact realistic, that Russell sees ethics as a sacrifice. As pointed out above cheating by the individual is not a rational stratagem in research. Either the researcher will be caught and the penalty is very high or the research itself will sooner or later be discredited. As phoney research will simply not stand up to any scrutiny. It is interesting that from the point of view of adding to the body of knowledge, cheating is irrelevant as it simply places the work in the category of poor or wrong findings and at the end of the day no-one will care much. This was well expressed by Gould (1982) when he said 'Fraud (in science) is not historically interesting except as gossip'.
Therefore all forms of cheating in research is, at least in the medium term, a waste of time.

By the way, looking at this issue from a completely different angle Oscar Wilde (1891) attempts to dispense with the issue of ethics in a rather cavalier way by saying that: 'No artist has ethical sympathies. An ethical sympathy in an artist is an unpardonable mannerism of style'.

However, irrespective of the plight of the artist, and it is sometimes argued that the researcher has much in common with the artist $^{24}$ (Rosenthal \& Rosnow, 1991), it is crucial to our modern world that there is a high standard of ethics as without this it would not be possible to operate the highly sophisticated large scale, high technology society which now exists. The operation of railways, airlines, local and international banks, police forces to mention only a few fundamental institutions would not be possible without a highly honed sense of morality and ethics and thus a mutually agreed view of what is right and wrong.

Irrespective of any particular individual's view of what is right or wrong many would agree that some notion of ethical behavior is important in research and especially in business and management research. The author believes that this is the case and suggests that one way to ensure a standard of ethics in research is to focus on the three principles of medical research (Jenkins, 1996) which may be translated in business and management research as follows:

1. ensure a high degree of respect for the autonomy of the individual;

2. work towards the benefication of society is a primary motivation of research; and

3. respects fairness.

Research ethics is a very challenging subject which the research candidate has to face, and which if not addressed correctly may cause the result of the research work to he considered tainted or even invalid. It is therefore necessary for the research candidate or scholar to clearly understand the ethical restrains which his or her community place on the way he or she conducts the research work and publishes the results. It is hoped that the above discussion will be helpful to researchers to understand the central issues involved and perhaps be of some assistance in setting a course through this difficult maze.

\section{Note}

1. According to the American heritage dictionary of the English language ethics - a. A set of principles for right conduct, b. A theory or a system of moral values. The former is the sense in which the word ethics is used in this article. This article does not address the ethical issues within any particular discipline such as that discussed by Walsham (1993), but rather it focusses on the ethics of the research process itself, without reference to any particular discipline in the field of business and management studies.

2. This view is much more relevant to doctoral work in the United Kingdom and continental Europe. In the United States of America a doctorate is much more an apprenticeship in research and thus a candidate does not really have to demonstrate that he or she is an authority in the field of study.

3. The subject matter of the research determines what is likely to be of value to the body of knowledge. With re- 
gards to business and management research economists distinguish between two main types of value which are described as value in use and value in exchange. In terms of research in the business and management arena. value in use is the priman objectuse $w$ ith value in exchange being a serendipitious event if it occurs. Thus if a PhD dissertation is published and bnings fame and fortune to the researcher this is ari additional bonus.

4. An example of professional research guidelines which support this vieu are those of the British Psychological Societ) (BPS,. The BPS guidelines stress that psychological research should be objective. competent and non-wasteful. Psychologists responsibilities include making their data and findings public but not in such a way that they may be misinterpreted or abused (Wadeley. 1991).

5. Prrmsier is a term used by some universities in place of supervisor. In some senses it more correctly reflects the function of the person which is assisting the doctoral candidate ohtyain his or her degree.

6. Despite this high level of trust or perhaps because of it. there is a certain amount of anecdotal evidence to suggest that some unethical practices are perpetrated by some candidates during the course of the degree. However it is generally believed that those involved in such behavior are in a small minority.

?. The Inust which is placed in business researchers is perhaps a result of the trus placed in research produced in the physical and life sciences. Because experiments performed in the physical and life sciences have to be repeatable it is difficult to cheat or present fraudulent results and attitudes resulting from this may have been picked up by business researchers.

8. Throughout this article the word evidence is used instead of data. The term data is regarded with suspicion by some researchers because it is derived for the Latin word $D o$. Do. Dare. Dedi. Datum is the Latin equivalent of the English vert to give. Thus the original meaning of data, which is the plural of datum. is given. Researchers need to ensure that the' minimize their assumptions or givens and in so doing they sometimes try to avoid the word data. The word evidence is regarded as a suitable substitute.

9. Although these experiments were condemned by many of the nations of the world and some of the leading Nazi's prosecuted at the Nuremberg Trials in 1946. many of the medical staff involved were never brought to justice and simply retumed to medical practice in Germany after the war.

10. Besides the ethics of how the evidence was collected in the Vazi concentration camps. there is also the ethical question of whether the finding of research which was conducted on the back of torture should be used by a civilized society. One vieu is that these findings should be ignored while others belief that it would be an affront to the pain and suffering of the victims not to make good use of the knowledge which their misery helped create. It could be believed that this debate is rather academic as once knowledge is created. no matter how. it is seldom possible to ignore or even control it. Thus Nazi concentration camp science lead to discoveries related to hip bone fractures which were added to the body of general medical science.

11. Stanley Milgram conducted researcher using 40 male volunteers who were told to teach a verbal task to another individual. in this case actors who were playing the role of would be leamers. and to give electric shocks. on an ascending scale of severity. for each incorrect answer. Although the shocks were phony. the actors pretended to be in severe pain. This experiment resulted in harm to a number of the volunteers who became very stressed by being expected to administer painful electric shocks to the so-called leamers. Many of the paricipants uere upset by the experiment and showed reactions ranging from nervous laughter to full-blown uncontrolled seizures' (Wadeley, 1991).

12. In terms of the Animals Scientific Procedures Act in the United Kingdom. a Home Office license is required before any experimental surgical or pharmacological nrocedures may be carried out on animals (Wadeley. 1991 ).

13. In the LSA there is a greater emphasis on experiments in business and management studies. These often involve students simulating the decisions made by managers

14. There may perhaps be one acceptable exception to this rule. Where a researcher is interested in studying issues related to the honesty and integrity of organizational behav. ior it would not be reasonable to expect an informant to declare that he or she behaved in a dishonest way. Thus some son of device would have to be used which would not be transparent to the informant. Clearly a reseanch study into the ethical practices of research degree candidates would require such treatment as it would be unreasonable to expect such researchers to admit to any questionable activities which would put their degrees at risk.

15. Triangulation should be a standard practice in any Masters or PhD degree project.

16. In the physical and life sciences data or evidence will often be kept indefinitely and the work will not be considered valid unless this data is available so that others can easily replicate the experiment.

17. Sir Cyril Burt who held a professorship at Lniversity College London, had a significant influence on education in the Lnited Kingdom and this lead to the eleven plus assessment system. It is now believed that his evidence was possible falsified. In fact Gould (1982) claims that Cyril Burt involved faked data complied by the non-existent $M s$ Connay. Burt actually said that he did not dispose of his evidence but that his evidence had been destroyed as a result of a bombing raid during the 1939-1945 war.

18. This point is somewhat controversial and some researchers would argue that all evidence collected has to be included in the final figures for the analysis.

19. The amount of difficulty perceived with eliminating personal bias from qualitative research may be a function of the background of the researcher. As a one time positivist on the road to conversion to a phenomenologist. the author feels that qualitative methods and bias are important issues. It is not intended to give the impression that the issue of personal bias and qualitative research detracts from the importance of this approach to research. Neither is it intended to suggest that quantitative research does not also have problems with the issue of personal bias. However it does seem to the author that due to the nature of the evidence being worked. qualitative research is more open to question on the issue of personal bias.

20. Although there is only anecdotal evidence to support the claim, it is said by colleagues both in the United Kingdom. continental Europe and in North America that there are 
quite different cultural interpretations of the notion of plagiarism. Degree candidates emanating from the developing countries seem to have a much less clear notion of the issue and its importance. Perhaps the problem with plagiarism is a good example of the issue described by Bertrand Russell and referred to in this article.

21. In the Department of Earth and Planetary Science at McGill University in Montreal, it is now customary for the supervisor and the $\mathrm{PhD}$ candidate to write the dissertation as a series of joint papers which are also submitted for publication to academic journals (Salvi, 1994). Here there is no suggestion that the work is exclusively that of the student, but rather a joint effort and thus the supervisor takes on the role of a promoter of the degree candidate. This arrangement clearly recognizes the reality of the shared nature of doctorate level research, which exists in many universities but which is not often openly admitted.

22. Some of the biotech companies make very large sums of money especially as much of the basic research has been done with government money before the project is commercialized.

23. Professor Trefor Jenkins of the South African Institute of Medical Research points out that this is not true in the case of medical research ethics where there is considerable agreement about what is right and what is wrong. However. although this may be true in general, there are still a number of issues especially in areas such as genetic engineering and whole body transplantation where there is considerable controversy.

24. The argument here is that the same sort of creativity is needed by both the researcher and the artist.

\section{References}

American heritage dictionary of the English language, 3rd Edition 1992 by Houghton Mifflin Company. Electronic version licensed from InfoSoft International, Inc.

Aristotle. 1976. Ethics, London: Penguin.

Collins, H. 1994. Does science matter - a broadcast video on Science Matters. United Kingdom: Open University, BBC.

Equinox-Dr Satin's robot. 1996. Broadcast by Channel 4 at 19:00 on Sunday 15 December.

Ewing, A.C. 1965. Ethics. New York: The Free Press, p.20.

Gould, S.J. 1980. The panda's thumb. London: W.W. Norton and Co.

Gould, S.J. 1992. The mismeasure of man. London: Penguin Books, p.20.

Haldane, J.B.S. 1927. On being ones own rabbit. In Possible worlds and other essays. Phoenix (1930). pp. 108, $109,113.115-116$.

Hubbard. R. 1979. Have only men evolved? In Hubbard, R., Henifin. M.S. \& Fried, B. eds. Women look at biology looking at women. London: Penquin .

Kant, I. 1948. The moral laws. London: Hutchinson.

Jenkins, T. 1996. A discussion with Professor Trefor Jenkins of the South African Institute of Medical Reseach in Johannes-burg, December.

Lacey, A. 1982. Modern philosophy. Boston: Routledge \& Kegan Paul, p.2.

Medawar, P. 1986. The limits of science. Oxford: Oxford University Press, pp. 32-33.

Miesing, P. \& Preble, J. 1985. A comparison of five busi- ness philosophies, Journal of Business Ethics, 6(8): 2629.

Mills, J. 1863. Utilitarianism. London: Everyman.

Remenyi, D. \& Williams, B. 1996. Some aspects of ethics and research into the Silicon Brain, International Journal of Information Management, 16(6): 401-411.

Rosenthal, R. \& Rosnow, R. 1991. Essentials of behavioral research. New York: McGraw Hill Inc.

Russell, B. 1946. A history of western philosophy: London: Unwin Hyman.

Russell, B. 1993. A free man's worship and other essays. In The Columbia dictionary of quotations, chapter 6 (1976). Columbia: Columbia University Press.

Salvi, S. 1994. Magna Degrassing and Wall Rock Alteration in the Rare Metal - Rich Peralkaline Granite at Strange Lake Quebec/Labrador. A thesis submitted to the Faculty of Graduate Studies and Research in partial fulfillment of the requirements of the degree of Doctor of Philosophy, Department of Earth and Planetary Science, McGill University, Montreal, Quebec, Canada.

Sekaran, U. 1992. Research methods for business - a skill building approach, 2nd ed. New York: John Wiley and Sons, p. 125.

Singer, P. 1994. Ethics - Oxford readers. Oxford: Oxford University Press.

Singer, P. 1995. Practical ethics, 2nd ed. Cambridge: Cambridge University Press. pp. 110-134.

Taylor, P. 1975. Principles of ethics - an introduction. New York: Dickson Publishing Company Inc.

The Guardian Weekly: 1988. The mathematician who turned down a $\$ 150,000$ prize. Le Monde section. May 15: 17 .

Trevelyan, G.M. 1993. British historian. (1876-1962), English Social History, Introduction (1942). In The Columbia dictionary: Columbia: Columbia University Press.

Wadeley, A. 1991. Ethics in psychological research and practice. Leicester: BPS.

Walsham, G. 1993. Ethical issues in information systems development: the analyst as moral agent. In Avison. Kendall \& DeGross. eds. Human, organizational and social dimensions of information systems development, ed. North Holland: Elsevier Science Publishers BV.

Wells, H.G. 1993. A modern Utopia, chapter 2. section 5 (1905; represented in The works of Wells, H.G. vol. 9. 1925). In The Columbia dictionary of quotations. Columbia: Columbia University Press.

Wheatley, M. 1992. Leadership and the New' Science. San Fransisco: Berrett-Koeler Publishers.

Wilde, O. 1993. The picture of Dorian Gray - Preface (1891). In The Columbia dictionary of quotations. Columbia: Columbia University Press.

Wittgenstein, L. 1990. Quoted from Tractatus Logico-Philosophicus (6.52) by Redpath. T. In Wittgenstein. L. A student's memoir. London: Duckworth, p. 36. 
Appendix 1 Practical CODE OF ETHICS for RESEARCH STUDENTS when collecting evidence and dealing with INFORMANTS

1. Research students should not begin the process of evidence collection for their research without previously discussing their evidence collection strategy with their supervisor or Head of Department.

2. When collecting evidence for the purposes of academic research towards a degree at the University students are representing the University and thus they are required to keep the University informed of whom they are approaching and why they have chosen these informants. Specifically, names and addresses, fax and phone numbers of all informants must be supplied to the Department secretary where possible in advance of the contact being made but research students should not miss a research opportunity because they could not inform the Department in advance.

3. The full purpose of the research will be declared by the researcher to all individual informants from which data will be collected.

4. Data collected for one purpose will not be used for any other without obtaining the permission of the informants for the alternative or additional use.

5. Where the informant has requested that the information should not be attributed to him/her or to his/her organization the researcher will ensure that these wishes are respected.
6. Where a researcher has a vested interest such as a bursary or scholarship or a family connection with a firm, the researcher will declare such interests when initially discussing with their supervisor or Head of Department and when approaching a potentially competitive firm for information. It is recommended that research students make every effort to avoid situations in which there is or may be any potential for a conflict of interest with informants.

7. Research students should not promise to supply the results of the research to informants as the results will only be formally released at the discretion of the Department. Research students should inform the Department of requests for research results and these will be attended to by the staff.

I have read the above Code of ethics. I understand what is required of me in selecting, approaching and dealing with evidence supplied by informants as a student of the Department of Information Systems at the University of Zanadu and I agree to comply with this Code of ethics.

Name (please prtnt)

Student No

Signature.

Date. 